Gut, 1973, 14, 697-700

\title{
Observations upon ammonia absorption from the human ileum
}

\author{
J. D. SWALES ${ }^{1}$, M. PAPADIMITRIOU, AND O. M. WRONG \\ From the Departments of Medicine, Manchester University, and University College Hospital School of \\ Medicine, London
}

SUMMARY Experiments have been performed upon the absorption of ammonia and hydrazine from different solutions instilled into a human ileal sac with an exteriorized stoma.

Ammonia and hydrazine absorption was greater from solutions of higher $\mathrm{pH}$. It is concluded that non-ionic diffusion plays an important role in ammonia absorption from the human ileum.

Ammonia is transported into the renal tubule by a process of passive diffusion in the non-ionic phase (Orloff and Berliner, 1956) with ionic trapping in the relatively acid tubular fluid. Likewise, the distribution of ammonia between blood and cerebrospinal fluid and between blood and gastrointestinal juices depends partly or wholly on the gradient in $\mathrm{pH}$ (Stabenau, Warren, and Rall, 1959; Fleshler and Gabuzda, 1965; Castell and Moore, 1971; Down, Agostini, Murison, and Wrong, 1972).

Price, Sawada, and Vorhees (1970) suggest that absorption of ammonia from the human ileum is likewise one of passive, non-ionic diffusion. However, Mossberg (1967) has claimed that the isolated ileal sac transports ammonia by an active, non-pHdependent mechanism. Kettering and Summerskill (1967) have compared the effects of pH and concentration gradients on ammonia movement in the human jejunum and also found evidence of absorption by a non-pH-dependent mechanism.

The purpose of the present work was to study the absorption of ammonia from an exteriorized human ileal loop with particular reference to $\mathrm{pH}$. In addition we have studied the absorption of hydrazine, a non-physiological substance which has physical properties similar to those of ammonia and which has been shown to be absorbed by non-ionic diffusion in other parts of the body (Coe and Korty, 1967; Bourke, Asatoor, and Milne, 1972).

\section{Methods}

The subject studied was a 27-year-old man with

${ }^{1}$ Address for correspondence: $\mathrm{Dr}$ J. D. Swales, Department of Medicine, Royal Infirmary, Manchester, M13 9WL.

Received for publication 31 May 1973. renal failure due to chronic pyelonephritis secondary to a neurogenic bladder which had followed spinal injury. He had undergone bilateral nephrectomy and an ileal loop had been constructed to receive eventually the ureter of the transplanted kidney. He was maintained on twice weekly intermittent haemodialysis whilst awaiting a suitable cadaveric donor. His informed consent for the experiments was obtained.

All experiments were started during the first hour of haemodialysis, when plasma urea ranged from 150 to $220 \mathrm{mg} / 100 \mathrm{ml}$, plasma potassium from 5.5 to 6.5 m-equiv/1, and bicarbonate from 20 to 23 m-equiv/1.

A double ballooned Foley-type catheter was placed so that one balloon was inside the pouch, and the other just outside; the ileal stoma was thus occluded. The loop was washed with the solution in use and emptied; $35-40 \mathrm{ml}$ of solution was then passed through the catheter into the loop. Thirty minutes was found to be the optimal time for each experiment, and at the end of this period the loop was emptied, the sample collected under paraffin, and frozen. In some experiments most of the fluid leaked back around the catheter, and these experiments were discarded.

All solutions contained $1.25 \mathrm{~g}$ of polyethylene glycol (mol wt 4000 )/100 $\mathrm{ml}$ as a non-absorbable marker. To prepare the solution, 0.2 molar Tris (Tris(hydroxymethyl)methylamine) was titrated either to $\mathrm{pH} 7.0$ or to $\mathrm{pH} 8.0$ with $0.1 \mathrm{~N}$ hydrochloric acid. Ammonium chloride (75 m-equiv/litre) and hydrazine $(400 \mu \mathrm{g} / \mathrm{litre})$ were added, together with sodium chloride to make the solution isotonic. The dose of hydrazine was chosen as being well below the maximum permitted level for industrial 
exposure, ie, 1 part per million. Fourteen experiments were performed with each of the two solutions.

The microdiffusion method of Conway (1962) was used for estimation of ammonia, bicarbonate was measured by the manometric method of Peters and Van Slyke (1932) and calculated from the HendersonHasselbalch equation; polyethylene glycol by the turbidometric method of Hyden (1956); hydrazine by the spectrophotometric method of Dambrauskas and Cornish (1962); osmolality by freezing point depression using a Knauer osmometer; pH was measured by a glass electrode meter.

\section{Results}

When isotonic saline was instilled into the ileal sac the fluid recovered contained insignificant amounts of ammonia (less than $0.5 \mathrm{~m}$-equiv/1).

The addition of ammonium chloride to the buffered solutions resulted in a slight lowering of $\mathrm{pH}$ so that the mean final $\mathrm{pH}$ of the two buffered solutions of ammonium chloride was 6.85 and 7.72. The absorption of ammonia corrected for the change in PEG concentration is shown in figure 1. The mean absorption of ammonia from the more acid of these solutions was $25.0 \%( \pm$ SEM $6 \cdot 7)$ and $44 \cdot 1 \%( \pm 3.5)$ from the solution of higher $\mathrm{pH}$. The difference between the two was statistically significant $(\mathrm{P}<0.05)$.

The pH 6.85 solution contained significantly less bicarbonate $(4.90 \pm 0.81 \mathrm{~m}$-equiv/1) at the end of the experiment than the solution buffered at $\mathrm{pH}$ $7 \cdot 72(6 \cdot 36 \pm 0 \cdot 38 \mathrm{~m}$-equiv/1).

Significantly more hydrazine was absorbed from the solution buffered at $\mathbf{7 \cdot 7 2}$ than from the solution buffered at 6.85 (mean absorption $=35.6 \%, \pm 3.7$ at $\mathrm{pH} 7 \cdot 72$ compared with a mean absorption of $16.0 \% \pm 3.1$ at $\mathrm{pH} 6.85, \mathrm{p}<0.05$ ) as shown in figure 2 .

\section{Discussion}

The initial $\mathrm{pH}$ of the solution significantly influenced the absorption of ammonia from the ileal sac of our patient (fig 1). The increased absorption of ammonia from the more alkaline solutions suggests that diffusion of ammonia in the non-ionic phase is playing a major role, as in the renal tubule (Orloff and Berliner, 1956; Milne, Scribner, and Crawford, 1958). Both the influence of $\mathrm{pH}$ upon ammonia absorption and the parallel change in bicarbonate secretion suggest a close similarity between the terminal ileum of the rat and man; wehave previously drawn attention to the formation in the rat ileum and human colon of the non-ionic pair by these two compounds which facilitates the absorp-

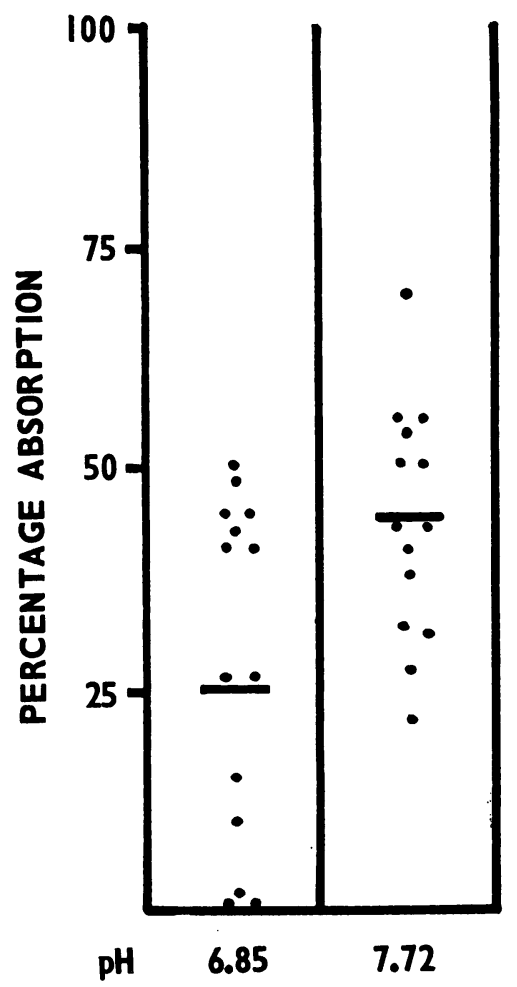

Fig 1 Percentage absorption of ammonia from the human ileum at two different $\mathrm{pH}$ levels.

tion of ammonia (Swales, Tange, and Wrong, 1970; Down et al, 1972).

There is a divergence between our results and those of Mossberg (1967), who concluded that ammonia was actively transported in vitro by the everted hamster ileal sac. This conclusion was based on the net movement of ammonia from the mucosal to the serosal side of the intestine which could be inhibited by sodium cyanide and 2:3 dinitrophenol and which did not appear to be influenced by the $\mathrm{pH}$ of the solutions bathing the preparation. This work, however, fails to take account of synthesis of ammonia and bicarbonate in vitro by the hamster ileal wall. Bicarbonate secretion by the ileal mucosa is an active metabolic process requiring the expenditure of energy, and will, therefore, be inhibited by the metabolic poisons used by Mossberg (1967). As the presence of bicarbonate facilitates non-ionic diffusion of ammonia (Swales et al, 1970), its absence as a result of metabolic inhibition would be expected to reduce ammonia absorption even if the latter were completely passive. It is noteworthy that Price et al (1970) also demonstrated a pH effect consistent with non-ionic diffusion in vitro.

The absorption of hydrazine exhibited a similar 
degree of $\mathrm{pH}$ dependence (fig 2). These results are consistent with our findings in the mouth (Swales, Kopstein, and Wrong, unpublished observations) and the rat ileum (Swales et al, 1970) and with observations by other workers on the kidney (Coe and Korty, 1967). It could be argued that both hydrazine and ammonia share the same active transport system. Hydrazine does, for instance, form glutamine analogues with glutamic acid. However, these compounds are much less readily formed in biological systems than the corresponding ammonium compounds (Willis, 1966). The clinical dissimilarity of hydrazine and ammonia, the similar $\mathrm{pH}$-dependent movement of both in different tissues, and the resemblance in essential physical properties (see table) all suggest that non-ionic diffusion plays a role in ammonia absorption. The similarity between ammonia excretion and the excretion of weakly basic drugs has been used to provide further support for non-ionic diffusion of ammonia in the kidney (Orloff and Berliner, 1956).

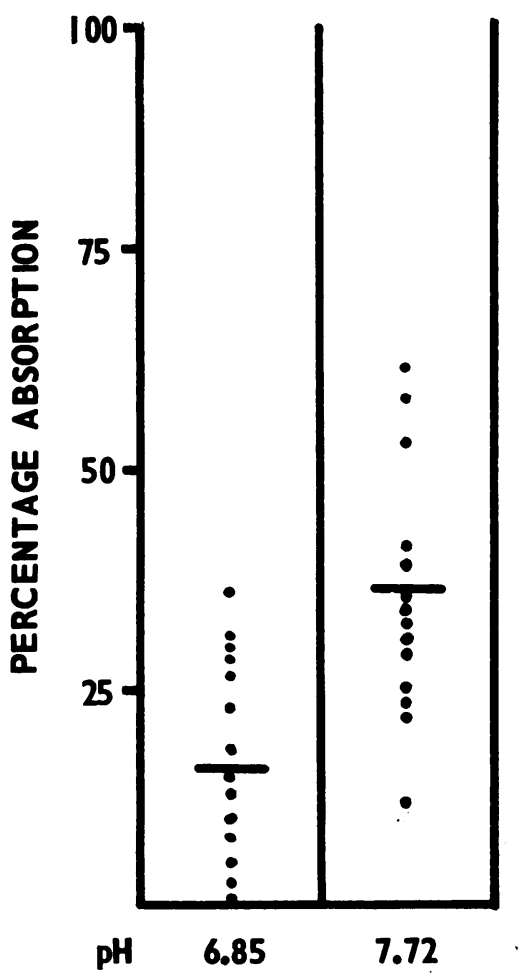

Fig 2 Percentage absorption of hydrazine from the human ileum at two different pH levels.

\begin{tabular}{llll}
\hline & Molecular Weight & $p K a$ & $\begin{array}{l}\text { Partition Coefficient } \\
\text { Chloroform/Water }\end{array}$ \\
\hline Ammonia & 17 & 9.25 & 0.05 \\
Hydrazine & 32 & 7.90 & 0.003 \\
\hline
\end{tabular}

Table Comparison of molecular weight, $p K a$, and partition coefficient of ammonia and hydrazine (from Bourke et al, 1972)

It is interesting that the absorption of drugs from the rat small intestine is influenced by $\mathrm{pK}$, lipid solubility of the drug in the nonionized phase, and the $\mathrm{pH}$ of the intestinal contents (Schanker, Tocco, Brodie, and Hogben, 1959).

The work presented therefore is consistent with the absorption of ammonia by a process of passive non-ionic diffusion. The relationship of the ileal sac studied here to the normal human ileum may be questioned. It is unlikely, however, that such a sac would handle ammonia in a qualitatively different way from normal ileum, particularly in view of the similarity of the observations reported here to those described in the rat ileum.

References

Bourke, E., Asatoor, A. M., and Milne, M. D. (1972). Mechanisms of excretion of some low-molecular-weight bases in the rat. Clin. Sci., 42, 635-642.

Castell, D. O., and Moore, E. W. (1971). Ammonia absorption from the human colon. Gastroenterology, 60, 33-42.

Coe, F. L., and Korty, P. R. (1967). Mechanism of hydrazine excretion by the mammalian kidney. Amer. J. Physiol., 212, 394-399.

Conway, E. J. (1962). Micro-diffusion Analysis and Volumetric Error, 5th revised ed., pp. 98-100. Crosby, Lockwood, London.

Dambrauskas, T., and Cornish, H. H. (1962). A modified spectrophotometric method for the determination of hydrazine. Amer. industr. Hyg. Ass. J., 23, 151-156.

Down, P. F., Agostini, L., Murison, J., and Wrong, O. M. (1972). The inter-relations of faecal ammonia, $\mathrm{pH}$ and bicarbonate: evidence of colonic absorption of ammonia by non-ionic diffusion. Clin. Sci., 43, 101-114.

Fleshler, B., and Gabuzda, G. J. (1965). Effect of ammonium chloride and urea infusions on ammonium levels and acidity of gastric juice. Gut, 6, 349-356.

Hyden, S. (1956). A turbidometric method for the determination of higher polyethylene glycols in biological materials. $K$. LantbrHögsk Annlr., 22, 139-145.

Kettering, R. F., and Summerskill, W. H. J. (1967). Comparison of effect of $\mathrm{pH}$ and concentration gradients on ammonia transport in the human jejunum. Medicine (Baltimore), 46, 91-96.

Milne, M. D., Scribner, B. H., and Crawford, M. A. (1958). Non-ionic diffusion and the excretion of weak acids and bases. Amer. $J$. Med., 24, 709-729.

Mossberg, S. M. (1967). Ammonia absorption in hamster ileum: effect of $\mathrm{pH}$ and total $\mathrm{CO}_{2}$ on transport in everted sacs. Amer. J. Physiol., 213, 1327-1330.

Orloff, J., and Berliner, R. W. (1956). The mechanism of the excretion of ammonia in the dog. J. clin. Invest., 35, 223-235.

Peters, J. P., and Van Slyke, D. D. (1932). Quantitative Clinical Chemistry, Vol II. Methods, pp. 285-296. Bailliere, Tindall, and Cox, London.

Price, J. B., Jr., Sawada, M., and Vorhees, A. B., Jr. (1970). Clinical significance of intraluminal $\mathrm{pH}$ in intestinal ammonia transport. Amer. J. Surg., 119, 595-598.

Schanker, L. S., Tocco, D. J., Brodie, B. B., and Hogben, C. A. M. (1959). Absorption of drugs from the rat small intestine. J. Pharmacol. exp. Ther., 123, 81-88. 

Stabenau, J. R., Warren, K. S., and Rall, D. P. (1959). The role of pH
gradient in the distribution of ammonia between blood and 373-383.

Swales, J. D., Tange, J. D., and Wrong, O. M. (1970). The influence of ammonia from the rat intestine. Clin. Sci., 39, 769-779.

Willis, J.E. (1966). The substitution of 1-methylhydrazine for ammonia in the glutamine synthetase system. Biochemistry (Wash.). $5,3557-3563$. 